\title{
Iatrogenia e exclusão social: a loucura como objeto do discurso científico no Brasil
}

\author{
Luís Gustavo Vechi \\ Universidade São Marcos
}

\begin{abstract}
Resumo
Este trabalho apresenta um retrospecto histórico sobre o discurso científico a respeito da loucura no Brasil, com destaque para a evolução das noções de doença mental e de iatrogenia. O discurso manicomial, eminentemente psiquiátrico, introduziu o gerenciamento científico da loucura, a partir do final do século XIX. De meados do século XX ao final da década de 80, o discurso da saúde mental, organizado pela Psiquiatria e por outras disciplinas, como a Psicanálise, a Sociologia e a Antropologia, sob a perspectiva biopsicossocial de compreensão do homem, representou uma nova tentativa de validar o gerenciamento científico da loucura. A partir do final da década de 80, foi introduzido o discurso da desinstitucionalização que, em vez de propor uma nova validação do discurso científico no gerenciamento da loucura, indicou a necessidade de sua (des)construção: uma radical operação epistemológica de modificação de suas concepções, como a de doença mental.
\end{abstract}

Palavras-chave: saúde mental; loucura; história; discurso; Brasil

\begin{abstract}
Iatrogeny and social exclusion: madness as an object of scientific discourse in Brazil. This paper presents a historical retrospective on the scientific discourse about madness in Brazil, emphasizing the evolution of the notions of mental disease and of iatrogeny. The manicomial discourse, produced by Psychiatry, has introduced the scientific management of madness since the end of the $19^{\text {th }}$ century. From the middle of the $20^{\text {th }}$ century until the end of 1980, the discourse of mental health, organized by Psychiatry and by other disciplines, such as Psychoanalysis, Sociology and Anthropology, using a biopsychossocial understanding of man, represented a new attempt to reinforce the scientific management of madness. At the end of 1980, the deinstitutionalization discourse was introduced and, instead of proposing a new validation for the scientific discourse on madness, it indicated the necessity of its (de)construction: a radical epistemological operation to modify some of its main notions, such as the notion of the mental disease.
\end{abstract}

Keywords: mental health; madness; history; discourse; Brazil

$\mathrm{O}$ objetivo deste artigo é apresentar um retrospecto a respeito de três tendências discursivas: a manicomial, a de saúde mental e a de desinstitucionalização, que marcaram o processo pelo qual a loucura se tornou e se mantém como objeto do discurso científico no Brasil. Esse histórico será realizado considerando-se, principalmente, as noções de doença mental e de iatrogenia, que tais discursos produziram.

Para a realização da tarefa ora proposta, o artigo será desenvolvido em três itens principais. No primeiro item, apresentaremos a loucura antes de ser objeto do discurso científico e, no segundo, a loucura como objeto do discurso científico, com as três tendências discursivas que a marcaram, já, no terceiro, teceremos considerações finais sobre a exposição teórica apresentada nas partes anteriores.

\section{A loucura antes de ser objeto do discurso científico.}

No Brasil, do século XVI ao início do século XIX, a loucura se fez presente no convívio social, sendo o seu portador apenas eventual e temporariamente encarcerado nas prisões públicas da época (Resende, 1990).

No entanto, a partir do início do século XIX, a loucura começou a ser reconhecida como desordem, perturbação da paz social e obstáculo ao crescimento econômico (Resende, 1990). Com isso, existiram "as mesmas circunstâncias sociais que, alguns séculos antes [nos séculos XVII e XVIII], determinaram na Europa, o que Foucault qualificou de 'o grande enclausuramento'; as diferenças residem apenas nas causas estruturais, aqui e lá, e que não foram poucas" (Resende, 1995, p. 35). 
No fim do século XVIII, na Europa, como Foucault (1972/1997) demonstrou, a loucura já era objeto de domínio do discurso científico (médico). Em 1793, Pinel havia assumido Bicêtre, em Paris; em 1789, Chiarugi o Hospital Bonifácio, na Itália; e Tuke, em 1792, na Inglaterra. Contudo, no Brasil do início do século XIX, a loucura passou a ser assunto do discurso religioso que, em associação com o governo, progressivamente, retirou-a do contexto social, isolando-a nas celas fortes dos porões de hospitais das Santas Casas de Misericórdia e nas prisões públicas (Figueiredo, 1996). Nessas instituições, a loucura era objeto de suporte espiritual e de correção moral. O que prevalecia, no entanto, eram os maus tratos, a repressão física e a falta de condições de higiene, o que condenava a maioria dos loucos à morte (Medeiros, 1977).

Dessa forma, do século XVI ao início do século XIX, de acordo com Figueiredo (1996), se "alguma política recaiu sobre o doente mental (...) esta foi a do controle social” (p. 169). Foi nesse período de nossa história que se iniciou a exclusão social da loucura, isto é, o processo, por intermédio do qual a loucura foi progressivamente desabitando o contexto social para ser confinada a lugares específicos (Machado, Loureiro, Luz, \& Muricy, 1978).

\section{A loucura como objeto do discurso científico}

Em meados do século XIX, o primeiro manicômio brasileiro, com o nome de Hospício D. Pedro II, foi inaugurado no Rio de Janeiro, capital do Império. Apesar da presença de médicos nesse local, o seu controle ainda permanecia objeto do discurso religioso praticado na Santa Casa. Após a proclamação da República, no final do século XIX, por meio do discurso científico (médico-psiquiátrico) associado ao Estado, a loucura foi retirada do discurso religioso. Assim, a loucura passou a ser gerenciada pelo discurso científico em serviços médicos especializados que foram sendo introduzidos no país na ocasião (Teixeira, 1997).

A possibilidade de ela se tornar objeto do discurso científico estava relacionada a um contexto progressivamente marcado no Ocidente pela "demanda de um novo homem, que será regulado nas suas ações e pretensões por uma nova Moral. Esta se inscreve nos códigos jurídicos, nas regras institucionais, no surgimento de novas instituições, nos discursos científico e filosófico" (Birman, 1978, p. 11). Esse mesmo autor propôs que a "Medicina mental emerge, como uma nova instituição social e como um discurso com pretensões científicas, neste momento de reorganização sociomoral do sujeito" (Birman, 1978, p. 11).

O processo, por meio do qual se legitimou (se legitima) a loucura como objeto do discurso científico, foi marcado por três tendências discursivas definidas a seguir.

\section{O discurso manicomial}

$\mathrm{O}$ discurso manicomial, que vigorou no Brasil a respeito da loucura, de meados do século XIX a meados do século $\mathrm{XX}$, foi aquele que introduziu a possibilidade de a loucura se tornar objeto do discurso científico no país. Esse discurso propunha substituir o gerenciamento religioso da loucura, na época identificado como primitivo e desumano, por um gerenciamento instituído pelo discurso científico (médico), firmado por meio de valores humanitários (Teixeira, 1997).

$\mathrm{O}$ discurso em questão se fez pela hegemonia do discurso médico, representado principalmente pela Psiquiatria, que se pretendia biológica. Por intermédio dele, foi introduzida uma das noções fundamentais para o processo de apropriação da loucura como seu objeto: a noção de doença mental (Portocarrero, 1990).

Com ela no discurso científico (médico), a loucura passou a ser definida como patologia, tanto de ordem moral como somática. A medicina se tornou, então, a instância definidora do estatuto do louco, como doente e como incapaz, portanto como sujeito a ser tratado e protegido. Apenas quando foi constituída uma inteligibilidade capaz de apreender e identificar a loucura como doença é que a Psiquiatria foi viável (Machado et al., 1978).

Com a noção de doença mental, a loucura foi (e ainda é) reduzida a estruturas, síndromes e diagnósticos baseados fundamentalmente nos aspectos ditos negativos da estrutura mental, como a alienação, a incompreensibilidade, a periculosidade e a incapacidade (Amarante, 1996). Além dessa restrição, a loucura ganhou uma outra, que se justifica mediante a primeira, isto é, a contingência social de habitar espaços de tratamento em serviços médicos especializados. O retorno do louco ao convívio social estava condicionado à possibilidade de uma adaptação mínima às regras do coletivo (Portocarrero, 1990).

Nesse período, o serviço especializado predominante foi aquele de tipo hospitalização integral de longa internação (Portocarrero, 1990). Todavia, esse tipo de serviço recebeu várias formas como: o manicômio pineliano, introduzido em meados do século XIX e o manicômio colônia, estabelecido no final do mesmo século. O segundo foi uma tentativa de asilamento em sistema de open-doors: sistema que permitia, principalmente, maior liberdade de circulação interna aos internados (Amarante, 1998b). Apesar da hegemonia dos serviços de tipo hospitalização integral, na década de 40 do século $\mathrm{XX}$, surgiu o primeiro ambulatório no Brasil, alternativa que, na década de 1960, chegou a compor dezessete unidades (Resende, 1990).

Embora houvesse a proposta dos serviços especializados de mudar a condição patológica da clientela, parte dela a eles submetida se mantinha no que se reconhecia como estado patológico. Essa realidade obrigou o discurso científico a fazer alguns "ajustes" em suas noções, a fim de poder se manter em cena, em que pese a impossibilidade de tratar e de modificar a condição de grande parte da clientela.

Um desses "ajustes" foi produzido mediante a noção de doença mental crônica, formulada no discurso científico. Assim, tal impossibilidade, ou seja, a perspectiva de cronicidade da patologia foi instituída, de um modo que não se permitiu descartar a necessidade de tratamento (Venancio, 1990).

Surgia a figura do crônico, que continha a especificidade de conciliar o princípio universal da curabilidade com a incurabilidade de fato. A renúncia ao par curabilidade- 
incurabilidade pela prevalência do primeiro termo, juntou-se à inserção da idéia de loucura na dimensão temporal, enquanto dimensão central da determinação da validade de qualquer terapêutica. E a cronicidade era expressão exatamente da maneira específica da alienação [definição de doença mental naquela época] perdurar no tempo em confronto com a idéia a priori da curabilidade [grifo da autora]. (Venancio, 1990, pp. 61-62)

Como podemos observar, com a perspectiva de cronicidade associada à noção de doença mental, pôde-se favorecer a manutenção do discurso científico no gerenciamento da loucura, a despeito da conservação no que se reconhecia como patologia. Além disso, foi cunhada uma definição para a loucura pela qual se antecipava o uso dos serviços especializados da época, porque era vista como patologia irreversível.

Com as reformas que ocorreram sob a égide do discurso manicomial, buscando fazer valer os princípios da cientificidade e dos valores humanitários no processo de apropriação da loucura como objeto do discurso científico, o louco continuou "encarcerado", ou seja, permaneceu numa condição social semelhante àquela produzida, quando o discurso religioso era o orientador. O gerenciamento científico da loucura com o discurso manicomial correspondeu, em grande parte, à exclusão e à tutela social da loucura.

Nos serviços de tipo hospitalização integral de longa duração do fim da década de 50 do século XX ainda havia "superlotação, deficiência de pessoal, maus tratos, condições de hotelaria tão más ou piores do que nos piores presídios, a mesma situação (...) [de] quase cem anos antes" (Resende, 1990, p. 55).

\section{O discurso da saúde mental}

De meados do século XX até a década de 1980, prevaleceu o discurso da saúde mental instituído como um discurso reformista, que propunha a substituição do discurso manicomial para concretizar, de uma vez por todas, a cientificidade e a humanização do tratamento no processo de gerenciamento da loucura (Portocarrero, 1990).

Esse saber foi constituído de alguns discursos médicos e, dentre eles, podemos mencionar o da Comunidade Terapêutica, o da Psicoterapia Institucional, o da Psiquiatria Comunitária, o da Psiquiatria Preventiva, o da Psiquiatria de Setor, entre outros, sendo-lhes agregado também o discurso de outras disciplinas como o da Psicologia, da Psicanálise, da Sociologia, da Antropologia, da Estatística e da Administração. A noção de doença mental permaneceu no discurso científico, mas passou a ser definida não apenas do ponto de vista somático ou moral, mas também de uma perspectiva multicausal denominada de biopsicossocial, que se pretendia representativa da totalidade da pessoa (Portocarrero, 1990).

Nas décadas de 1980 e de 1990, no entanto, a Psiquiatria Biológica ressurgiu com grande força, propondo novamente uma perspectiva eminentemente somática a respeito da doença mental. A Psiquiatria Biológica ganhou novo fôlego principalmente devido aos avanços científicos, tais como: novos psicofármacos, exames com ressonância nuclear magnética, tomografia por emissão de pósitrons, por emissão de fóton simples, mapeamento da atividade elétrica cerebral, descrição de novos receptores do sistema nervoso central, entre outros, que lhe permitiram se aproximar da clínica médica. Essa perspectiva somática da doença mental trouxe uma maior valorização do tratamento médico pautado na psicofarmacologia, processo que tem sido denominado de remedicalização da Psiquiatria (Serpa Jr., 1992).

Apesar dessa tendência somática de limitação da patologia, a sua multicausalidade ainda foi proposta, seguindo-se o tratamento prescrito com procedimentos específicos que englobassem a dimensão biopsicossocial. O foco prioritário do tratamento era a produção de saúde mental e não apenas o tratamento e a modificação da patologia, como no discurso manicomial. A produção de saúde mental circunscrita prioritariamente como adaptação social substituiu o objetivo anterior de intervenção na doença.

A família da clientela atendida, antes afastada do tratamento, passou a fazer parte de sua terapêutica. E, ainda que o discurso científico e o do governo tenham proposto serviços especializados de tipo hospitalização parcial, aqueles de tipo hospitalização integral de longa internação permaneceram hegemônicos no Brasil dessa época (Portocarrero, 1990).

No discurso da saúde mental, foi introduzida a noção de iatrogenia que, por hipótese, atribuía aos serviços de saúde mental o efeito de favorecer a conservação da clientela no que se reconhecia como patologia (Portocarrero, 1990).

Nessa noção, ainda utilizada no discurso científico atual, fatores presentes no atendimento em saúde mental são associados à produção de patologia de ordem psíquica na clientela, ou melhor, de uma patologia diferente daquela inicial que motivou a procura de tratamento. A iatrogenia propiciaria à clientela atendida manter-se numa condição psíquica reconhecida pelas ciências da saúde mental - principalmente a Psicologia e a Psiquiatria - como patológica e naquela de ser tratada em serviço de saúde mental (Caplan \& Caplan, 2001; Morris, 1992).

Mediante essa noção articulada no discurso científico, o ambulatório e os serviços de tipo hospitalização integral passaram, dessa forma, a ser vistos em seu potencial de produção de efeito adverso ao terapêutico proposto. Com isso, a suposta tendência natural de "conservação", no que se reconhecia como patologia contida na perspectiva de cronicidade, passou a ser também considerada como um processo produzido no próprio tratamento por intermédio da hipótese de iatrogenia. Essa noção foi sustentada no discurso da saúde mental no Brasil, principalmente, por se pautar pelas idéias defendidas por Basaglia e Goffman (Portocarrero, 1990; Venancio, 1990).

Segundo Delgado (1991),

Goffman, cujo "Asylums” só foi traduzido no Brasil no início dos anos 70, passou a fornecer a argumentação que sustentava, descritivamente, o impacto do hospital psiquiátrico sobre a evolução clínica (...) do paciente. A evolução deixava de pertencer à "história natural" da loucura medicalizada para ser imputada à própria rotina do cuidado institucional. (p. 119) 
Em Goffman (1961/1999), importante referência teórica para a noção em questão, o produto da iatrogenia foi especificado como modificações no âmbito psíquico da clientela, as quais incidiriam na auto-imagem, na autoconfiança, nas crenças pessoais e na forma de ela se relacionar socialmente. Ocorreria o que esse autor definiu como profanação do eu, ou como despersonalização do cliente atendido.

Essas alterações produziriam uma adaptação excessiva do usuário ao papel de doente mental. Em outros termos, haveria a criação de uma dependência excessiva ao atendimento psiquiátrico e uma concomitante diminuição da vontade e do repertório necessários para o convívio social. Isso, por sua vez, traria como resultado da iatrogenia a carreira moral do doente mental, definida como a contingência de o usuário de saúde mental restringir sua existência ao contexto terapêutico ou àqueles associados a ele (Goffman, 1961/1999).

A "patologização" institucional foi associada às características prisionais dos serviços de tipo hospitalização integral de longa duração, como o isolamento social, a longa permanência, os maus tratos, a forma como a clientela era definida e compreendida, entre outras (Delgado, 1991).

Como exemplo de utilização da hipótese de iatrogenia nessa segunda fase do processo de gerenciamento científico da loucura, encontramos a dissertação de mestrado de Moreira (1983), que a desenvolveu com referência a serviços de tipo hospitalização integral de longa duração no final da década de 1970, em Minas Gerais.

No âmbito discursivo, marcado pela hipótese de que o serviço especializado seria produtor de efeito iatrogênico, o discurso da saúde mental no Brasil foi firmado como possibilidade de "resolver problemas derivados da própria prática assistencial, sobretudo a iatrogenia e a cronificação institucional" (Portocarrero, 1990, p. 2).

Nessa época, algumas proposições foram feitas por profissionais de saúde mental do Movimento dos Trabalhadores de Saúde Mental (MTSM), importante agente enunciador do discurso da saúde mental. (Amarante, 1998b). A partir desse momento, o MTSM tornou-se importante transformador da saúde mental, com expressivo papel na proposição de novas políticas públicas para essa área.

No entanto, essas proposições resumiram-se, em sua maioria, em soluções de caráter sanitarista: controles epidemiológicos, padrões de atendimento, sistemas de referência e de contra-referência entre serviços, entre outros. A otimização de recursos, principalmente daqueles de ordem administrativa, foi o caminho escolhido para se reverter o quadro de superlotação, ineficiência e iatrogenia em que se encontravam os serviços da época. Para se ter uma idéia, o item hotelaria (abrigar e vestir bem o doente) era mais importante do que a qualidade terapêutica e de pessoal para o credenciamento de serviços à rede pública. Pouco foi considerado da relação entre usuário e profissional e muito sobre estatísticas de populações (Amarante, 1998b).

Apesar das proposições feitas e de algumas modificações concretas como a introdução da moderna psicofarmacologia, os recursos da Previdência Social estavam destinados prioritariamente à compra de serviços hospi- talares privados que não acatavam as instruções normativas do INPS. Com parcos investimentos nos serviços públicos, a rede de hospitais não tinha como desenvolver uma política própria e a Previdência Social estava a serviço da iniciativa privada, que não permitia o avanço de programas considerados não-hospitalizantes (Amarante, 1998b).

As internações nos serviços de tipo hospitalização integral ainda eram demasiado longas e, em grande parte deles, predominavam os maus tratos, a ausência de intervenções terapêuticas, condições precárias de hotelaria, superlotação, incapacitação da mão-de-obra (Resende, 1990). O ambulatório, único serviço de tipo "extra-hospitalar", foi pouco enfatizado, na medida em que funcionava apenas como ponte para a internação e, por isso, em nada alterou o ciclo internação-alta-internação (Portocarrero, 1990).

"Ao lado de tentativas de mudança nas instituições asilares, e, sobretudo, da busca de 'desconstrução' do asilo (baseada nos princípios da Psiquiatria Comunitária, social [...]), permanece quase inalterada a estrutura de atendimento" (Portocarrero, 1990, p. 184). A característica comum a todas as experiências de serviços comunitários no Brasil foi "a sua marginalidade. São experiências locais, referidas a um ou outro serviço, a um ou outro grupo. Tão à margem das propostas e dos investimentos públicos efetivos, que suas memórias são de difícil, senão de impossível resgate" (Amarante, 1998a, p. 79).

As reformulações psiquiátricas encontradas na Europa e nos EUA (a partir de meados do século XX) são levadas em consideração diante do quadro trágico encontrado em todas as instituições brasileiras especializadas em Saúde Mental. Contudo, reduzem-se a uma aplicação prática nula - ou simplesmente restrita a uma pequena elite "reformadora" ou "inovadora" quando se trata de Saúde Pública. (...) Conservam-se (...) instituições coercitivas, de intervenções diretas e freqüentemente violentas por parte do poder do Estado, no sentido de impedir que práticas diferentes se exerçam de imediato (...) a prática psiquiátrica permanece prevalentemente clássica [manicomial]". (Portocarrero, 1990, pp. 75, 163, 167)

Os serviços especializados continuaram, como naqueles característicos do discurso manicomial, a representar quase que exclusivamente o "encarceramento", desempenhando a função de exclusão e de tutela social da loucura. "A formulação da existência dessa continuidade não implica absolutamente o reconhecimento da produção de algumas descontinuidades, mas estas se inscrevem na periferia" (Birman, 1992, p. 83). As modificações introduzidas com o discurso da saúde mental foram suficientemente estratégicas para manter a Psiquiatria no cenário social, mas rasas para uma real transformação no processo de gerenciamento científico da loucura.

Desse modo, sob a égide do discurso da saúde mental se

apresenta a partir de novas justificativas "científicas", (...) uma prática assistencial que permanece essencialmente a mesma - asilar, tutelar e custodial - mas que já não se sustenta sem uma mudança em seu discurso e, até certo ponto, de sua ação, na medida em que é deflagrado o seu comprometimento com 
uma função iatrogênica e cronificadora. [grifos nossos] (Portocarrero, 1990, p. 190)

Podemos concluir que, a despeito das sucessivas reformas psiquiátricas brasileiras que ocorreram, desde o início do gerenciamento científico da loucura, até o final da década de 1980, predominou a produção do lugar de exclusão social da loucura por intermédio do seu asilamento em serviços especializados de tipo longa internação ou ambulatoriais ineficazes (Amarante, 1998, Portocarrero, 1990).

\section{$O$ discurso da desinstitucionalização}

Já no final da década de 1980, o Brasil encontrava-se com uma nova tendência discursiva: o discurso da desinstitucionalização, instituído, sobretudo, a partir do discurso médico italiano da Psiquiatria Democrática. Nessa época, Foucault, Basaglia, entre outros, foram reinseridos no discurso a respeito da assistência à saúde mental. Esse procedimento substituiu o discurso relacionado à tendência sanitarista do movimento de reforma anterior. Os hospitais-dia começaram a ser utilizados na assistência pública à saúde mental no Brasil, e os serviços de tipo internação integral reformulados (Amarante, 1998b).

Essa tendência discursiva foi sendo divulgada pelo Movimento dos Trabalhadores em Saúde Mental. Esse movimento foi, e é, importante agente de transformação, com expressiva participação na definição das políticas públicas na área da saúde mental. Os que fizeram parte dessa terceira etapa da reforma apontaram a superficialidade das proposições, como também a ausência de modificações efetivas no discurso da saúde mental. Esse movimento introduziu uma nova abordagem crítica a respeito do gerenciamento da loucura, que passou a ter como objeto de modificação o próprio discurso científico. Se, nos discursos anteriores, as reformas propostas limitavam-se à otimização de recursos, visando à aproximação do processo de gerenciamento da loucura, do que se reconhecia como científico e humanitário, já, no discurso da desinstitucionalização, propôs-se tomar o próprio discurso científico, fundador do referido processo, como alvo de avaliação crítica (Amarante, 1998b).

Com esse movimento, passou-se a considerar que

não bastam as medidas racionalizadoras, de princípios de boa gestão administrativa, de diagnóstico comunitário, de hierarquização, de descentralização de serviços, de regionalização, de sistemas de referência e contra-referência, de participação comunitária e assim por diante, se não se operam mudanças na natureza do saber que se exercita no que se está conceituando como ato de saúde (Amarante \& Giovanella, 1998, p. 139).

Os envolvidos nesse processo de reforma difundiram a abordagem crítica a respeito do discurso científico, como etapa importante para a produção de efetivas mudanças na situação da loucura no Brasil. Propuseram, assim, retomar, dentre outras, a secular noção de doença mental do discurso científico como objeto de (des)construção. Essa noção passou a ser questionada naquela acepção que a considerava como representação de algo que está no corpo ou no psiquismo de uma pessoa, pois foi percebida - acima de tudo - como uma construção política e teórica, institucional e científica (Luz, 1998).

Nesses termos, o discurso basagliano da desinstitucionalização apontou para a necessidade de uma complexa modificação científica e social. Esse discurso indicou a necessidade de uma desconstrução, e não apenas de uma reforma, entendida como melhora e humanização dos três pilares principais que sustentam o lugar de exclusão social da loucura: a vigente organização dos serviços de saúde mental, o discurso científico, sobremodo no que se refere à noção de doença mental e o contexto social, que condiciona o isolamento do desvio à norma (Amarante, 1994, 1996).

Alguns estudos acadêmicos com propostas metodológicas distintas entraram em sintonia com a abordagem crítica a respeito do discurso científico, como proposto pela desinstitucionalização. Dentre eles, podemos citar o que foi elaborado por Scarcelli (1998).

Em sua dissertação de mestrado, essa pesquisadora estudou supervisões de equipes de profissionais dos serviços da rede substitutiva de saúde mental da Prefeitura de São Paulo durante o final da década de 1980 e início da década de 1990. A autora demonstrou que o caráter manicomial dos serviços é, em parte, produzido pelos limites de exclusão e de normatização de condutas da noção de doença mental. Nessa noção, encontramos a lógica do saber psiquiátrico tradicional, baseada em critérios de exclusão, normatização, classificação e medicalização. Ela concluiu que a tentativa de abandono da concepção clássica de doença mental pode trazer, como consequiência, a possibilidade de encontrarmos formas alternativas à manicomial no trato ao indivíduo portador de sofrimento mental.

A hipótese de que os serviços de saúde mental de tipo hospitalização integral de longa duração podem produzir efeito adverso ao terapêutico, ou seja, efeito iatrogênico que favoreceria a conservação da clientela no que se reconhecia como patologia continuou vigente no discurso da desinstitucionalização.

Como exemplo da utilização da hipótese de iatrogenia nessa época, encontramos o artigo de Delgado (1991), que versou a respeito dos dispositivos institucionais de iatrogenia. Para esse autor, o discurso da Psiquiatria Democrática foi importante para a manutenção dessa hipótese. A asserção que atribui a cronicidade ao asilo é, entretanto, recente e se nutre da retórica da Psiquiatria Democrática Italiana. A hipótese de iatrogenia não foi considerada por ele, apenas para os serviços de tipo hospitalização integral de longa duração, mas também para o ambulatório.

Apesar da presença dessa terceira tendência discursiva, existe o risco de as propostas públicas de assistência à saúde mental, bem como as pesquisas acadêmicas sobre esse tema reduzirem a noção de desinstitucionalização ao mero processo de desospitalização. Nesse sentido, essa noção apontaria apenas para a necessidade de mudança do locus de tratamento, isto é, dos grandes hospitais psiquiátricos para os serviços comunitários, como os hospitais-dia e os centros de atenção psicossocial (Amarante, 1998b). 
A bibliografia internacional aponta para o potencial iatrogênico de serviços comunitários como o hospital-dia (Vechi, 2003). Um estudo brasileiro demonstrou a permanência de um discurso científico que reproduz algumas das características do discurso manicomial no processo de atendimento à clientela em hospital-dia. A noção de doença mental é utilizada de uma forma a invalidar a condição de sujeito (autônomo) do usuário. Existem certas marcas associadas pela literatura científica com a iatrogenia no discurso produzido por agentes desse tipo de serviço (Vechi, 2003).

Nesses termos, uma apropriação reducionista do discurso da desinstitucionalização poderia nos levar a apostar novamente num tipo de mudança no gerenciamento científico da loucura, que não parece ser suficiente para romper com os processos de iatrogenia, isto é, de conservação da clientela atendida em uma condição reconhecida como patológica e na de permanecer usuário dos serviços de saúde mental.

\section{Considerações Finais}

No retrospecto histórico exposto acima, destacamos as noções de doença mental e de iatrogenia como marcos conceituais no processo de inserção (e de manutenção) da loucura como objeto do discurso científico. Após termos desenvolvido algumas questões importantes acerca dessas noções, por intermédio da apresentação do discurso manicomial, da saúde mental e da desinstitucionalização, concluímos que, apesar de sucessivas reformas discursivas e dos procedimentos assistenciais associadas a ela, o efeito de favorecer a permanência em uma condição reconhecida como patológica foi um aspecto presente no processo de introdução e manutenção da loucura como objeto da ciência.

Como já observamos, a compreensão sobre a conservação do indivíduo na patologia foi diversa nos três discursos apresentados. O discurso da saúde mental avançou nessa compreensão, quando comparado com o seu antecessor, o discurso manicomial, pois conjetura a possibilidade de a conservação na patologia estar relacionada com a organização do tratamento oferecido. No entanto, esse discurso propõe soluções de caráter reformista para a assistência à saúde mental, ou seja, se atém a definir mudanças nas organizações de saúde mental e retificações na noção de doença mental.

O discurso da desinstitucionalização, por sua vez, introduz a possibilidade de analisarmos e modificarmos o processo institucional de patologização, porque ele nos convida a enfocar a base do processo de gerenciamento científico da loucura, para definirmos a iatrogenia. Ou melhor, ele nos convida a pôr em cena o discurso científico com os seus maiores cânones conceituais - como as noções de doença mental, de tratamento, de reabilitação - porque é por meio deles que se inauguram e se justificam os procedimentos assistenciais que podem isolar, estigmatizar, excluir, enfim, "patologizar" a pessoa.

Desse modo, o próprio discurso científico, tal como formulado na tendência anterior - da saúde mental - é visto como um importante fator na geração de procedimentos de atenção à saúde mental, de concepções de saúde e de doença no contexto cultural, de formas de relacionamento com a pessoa reconhecida como "doente mental" no contexto social, que são propícias a gerar o que a literatura define como iatrogenia. A geração de iatrogenia está relacionada ao modo de se definir, compreender, especificar a loucura, bem como aos rumos estabelecidos para ela no contexto social.

Nesses termos, a noção de iatrogenia pôde ser ampliada e entendida não apenas como resultado de uma assistência insuficiente ou inadequada, como propõe o discurso da saúde mental, mas como um subproduto de uma assistência, baseada em um discurso científico que tem favorecido a "patologização" da clientela atendida.

Com o discurso em questão, levantamos a hipótese de que esse efeito "patologizador" foi (e talvez ainda seja) um vetor próprio, e não apenas um subproduto condenável no processo pelo qual a loucura se tornou objeto do discurso científico. Porque, por seu intermédio, com a produção de iatrogenia, favoreceu-se a conservação da pessoa reconhecida como louca na patologia e na contingência de ser usuária de serviço de saúde mental. E, com a conservação na doença, perpetuaram-se as condições que legitimaram (e legitimam) a continuidade do domínio do discurso científico sobre a loucura, ou seja, mantiveram-se as condições objetivas, por meio das quais, promoveu-se e justificou-se a conservação da loucura em tratamento. Mantida na contingência de tratamento, ela permaneceu, em certo nível, limitada em sua amplitude de circulação no contexto social.

Posto isso, concluímos que o discurso da desinstitucionalização parece ser aquele que contém uma proposta capaz de reverter o secular processo de iatrogenia, porque indica a necessidade de se desconstruir as bases do gerenciamento científico da loucura e dos meios de produção de sua eterna institucionalização.

Esse discurso, assim, diferentemente dos demais, propõe a (re)invenção na forma de definirmos, olharmos, caracterizarmos, compreendermos a loucura. Tal (re)invenção parece ser possível, se contarmos com (e tivermos a ousadia de aceitar e construir) noções científicas que permitam definir e enxergar a loucura, sem restringi-la à ordem da patologia.

Essas noções resgatariam a possibilidade de se definir as diferenças e o sofrimento, sem necessariamente fazer uso do viés do desvio, da incapacidade, da anormalidade, da periculosidade, da incompetência, da incapacidade e, como conseqüência, da normalização terapêutica. Essas noções ainda recobrariam a verdade e a diversidade da existência humana contida na condição reconhecida como loucura.

Com essa nova perspectiva, o discurso científico e a rede de procedimentos de cuidado propostos, contarão com novas possibilidades para se relacionar com o que ultrapassa os limites da razão e é definido como loucura. Poderemos favorecer, com isso, a construção de um novo lugar social para a pessoa reconhecida nessa condição, e não apenas a fabricação de novos espaços terapêuticos.

\section{Referências}

Amarante, P. (1996). O homem e a serpente: outras histórias para a loucura e a psiquiatria. Rio de Janeiro: Fiocruz. 
Amarante, P. (1998a). Asilos, alienados e alienistas. In P. Amarante (Org.), Psiquiatria social e reforma psiquiátrica (pp. 73-84). Rio de Janeiro: Fiocruz.

Amarante, P. (1998b). Loucos pela vida: a trajetória da reforma psiquiátrica no Brasil ( $2^{\underline{a}}$ ed.). Rio de Janeiro: Fiocruz.

Amarante, P., \& Giovanella, L. (1998). O enfoque do planejamento em saúde e saúde mental. In P. Amarante (Org.), Psiquiatria Social e Reforma Psiquiátrica (pp. 113-148). Rio de Janeiro: Fiocruz.

Birman, J. (1978). A psiquiatria como discurso da moralidade. Rio de Janeiro: Graal

Birman, J. (1992). A cidadania tresloucada. In B. Bezerra \& P. Amarante (Orgs.), Psiquiatria sem hospício: contribuições ao estudo da reforma psiquiátrica (pp. 71-90). Rio de Janeiro: Relume Dumurá.

Caplan, B. R., \& Caplan, G. (2001). Helping the helpers not to harm: iatrogenic damage and community mental health. Nova York: Brunner-Routledge.

Delgado, P. G. G. (1991). Determinantes institucionais da cronificação. Jornal Brasileiro de Psiquiatria, 40, 117-125.

Figueiredo, G. R. (1996). A evolução do hospício no Brasil. Tese de Doutorado não-publicada, Universidade Federal de São Paulo, São Paulo.

Foucault, M. (1997). História da loucura na idade clássica (5ª $5^{\mathrm{a}}$ ed.). São Paulo: Perspectiva. (originalmente publicado em 1972)

Goffman, E. (1999). Manicômios, prisões e conventos (6 $6^{\underline{\mathrm{a}}}$ ed.). São Paulo: Perspectiva. (originalmente publicado em 1961)

Luz, M. T. (1998). A história de uma marginalização: a política oficial de saúde mental. In P. Amarante (Org.), Psiquiatria social e reforma psiquiátrica. (pp. 85-95). Rio de Janeiro: Fiocruz.

Machado, R., Loureiro, A., Luz, R., \& Muricy, K. (1978). Danação da norma: medicina social e constituição da psiquiatria no Brasil. Rio de Janeiro: Graal.
Medeiros, T. A. (1977). Formação do modelo assistencial psiquiátrico no Brasil. Dissertação de Mestrado não-publicada, Universidade Federal do Rio de Janeiro, Rio de Janeiro.

Moreira, D. (1983). Psiquiatria: controle e repressão social. Petrópolis: Vozes.

Morris, C. (Org.). (1992). Academic press dictionary of science and technology. Nova York: Academic.

Portocarrero, V. (1990). O dispositivo da saúde mental: uma metamorfose na psiquiatria brasileira. Tese de Doutorado não-publicada, Universidade Federal do Rio de Janeiro, Rio de Janeiro.

Resende, H. (1990). Política de saúde mental no Brasil: uma visão histórica. In S. A. Tundis \& N. R. Costa (Orgs.), Cidadania e loucura: políticas de saúde mental no Brasil (pp. 15-73). Petrópolis: Vozes.

Scarcelli, I. R. (1998). O movimento antimanicomial e a rede substitutiva em saúde mental: a experiência do município de São Paulo. Dissertação de Mestrado não-publicada, Universidade de São Paulo, São Paulo.

Serpa Jr., O. D. (1992). A constituição de um olhar: a experiência clínica na medicina e na psiquiatria. Dissertação de Mestrado não-publicada, Universidade Federal do Rio de Janeiro, Rio de Janeiro.

Teixeira, M. O. L. (1997). Nascimento da psiquiatria no Brasil. Cadernos IPUB, $8,42-78$.

Venancio, A. T. A. (1990). Sobre a "nova psiquiatria" no Brasil: um estudo de caso do hospital-dia do Instituto de Psiquiatria. Dissertação de Mestrado não-publicada, Universidade Federal do Rio de Janeiro, Rio de Janeiro.

Vechi, L. G. (2003). A primeira internação no discurso de agentes de saúde mental de hospital-dia: uma leitura institucional. Dissertação de Mestrado não-publicada, Universidade de São Paulo, São Paulo.

Luís Gustavo Vechi, mestre em Psicologia e doutorando em Psicologia Escolar e do Desenvolvimento da Personalidade no Instituto de Psicologia da Universidade de São Paulo, é psicólogo clínico no Centro de Atenção Psicossocial Professor Luís da Rocha Cerqueira e professor na Universidade São Marcos. Endereço para correspondência: Avenida Irerê, 2030, ap. 504 (Planalto Paulista); São Paulo, SP; CEP 04064-005. Tel.: (11) 5594-4861.E-mail gvechi@ig.com.br 